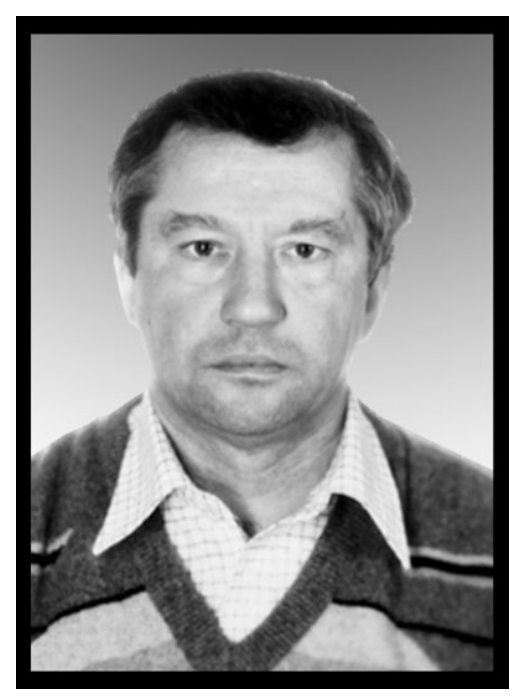

\title{
To the memory of Mikhail Yuvenalievich Antipin
}

On February 18, 2013, Corresponding Member of the Russian Academy of Sciences Mikhail Yuvenalievich Antipin, a well-known authority in structural chemistry and crystal chemistry, passed away at the age of 61 .

M. Yu. Antipin graduated from the Department of Chemistry of the Moscow State University in 1973, and since 1976, he worked at the A. N. Nesmeyanov Institute of Organoelement Compounds, at the Laboratory for X-Ray Diffraction Studies, which was headed at that time by Corresponding Member of the Russian Academy of Sciences Yu. T. Struchkov. Under Struchkov's supervision, M. Yu. Antipin got the Ph.D degree, and in 1989, he became Doctor of Sciences. During this period, M. Yu. Antipin actively participated in the development of methods for low-temperature X-ray diffraction studies of the structures of crystals, including unstable and low-melting compounds, in the development of experimental methods for investigation of electron density distribution, which provided more profound approach to understanding of the nature of the chemical bond.

These works were rewarded by the E. S. Fedorov Prize of the Academy in 1992 and by the P. L. Kapitsa Prize of the Royal Chemical Society (London) in 1994. In 1997, M. Yu. Antipin was elected Corresponding Member of the Russian Academy of Sciences in the specialty "Physical Chemistry".

M. Yu. Antipin made a substantial contribution to the development of structural chemistry of phosphorus, silicon, fluorine, boron, and some transition metal compounds. He published a multitude of scientific papers and reviews and trained more than $30 \mathrm{Ph}$.Ds and Doctors of Sciences. After. Yu. T. Struchkov deceased in 1995, he successfully headed the Laboratory for X-Ray Diffraction Studies and a top scientific school in the field of physical methods for investigation of chemical compounds. He was among organizers and permanent chairman for 14 years of the international Struchkov Prize Society, which supports young crystallography and crystal chemistry scientists of the former USSR.

M. Yu. Antipin was a member of the Editorial Boards of the journals Russian Chemical Bulletin (Izvestiya Akademii Nauk. Seriya Khimicheskaya), Russian Chemical Reviews (Uspekhi khimii), and Crystallography Reports (Kristallografiya); he participated in the activity of the Russian Foundation for Basic Research, in the organization of scientific conferences where he often presented plenary or invited lectures.

The cherished memory of Mikhail Yuvenalievich Antipin is preserved by his followers, colleagues, and friends. 